NBER WORKING PAPER SERIES

\title{
WHY DON'T LENDERS RENEGOTIATE MORE HOME MORTGAGES? REDEFAULTS, SELF-CURES AND SECURITIZATION
}

\author{
Manuel Adelino \\ Kristopher Gerardi \\ Paul S. Willen \\ Working Paper 15159 \\ http://www.nber.org/papers/w15159
}

\author{
NATIONAL BUREAU OF ECONOMIC RESEARCH \\ 1050 Massachusetts Avenue \\ Cambridge, MA 02138 \\ July 2009
}

We thank John Campbell, Chris Foote, Scott Frame, Anil Kashyap, Chris Mayer, Eric Rosengren, Julio Rotemberg, and seminar audiences at Freddie Mac, Harvard Business School, University of Connecticut, LSE, the SAET meetings in Ischia, ESSET-Gerzensee, and the MIT Finance Lunch for thoughtful comments, Kyle Carlson and Suzanne Lorant for editorial help, and the Studienzentrum Gerzensee, where the authors completed this paper, for their generous hospitality. The views expressed herein are those of the author(s) and do not necessarily reflect the views of the National Bureau of Economic Research, the Federal Reserve Banks of Atlanta or Boston or the Federal Reserve System.

NBER working papers are circulated for discussion and comment purposes. They have not been peerreviewed or been subject to the review by the NBER Board of Directors that accompanies official NBER publications.

(C) 2009 by Manuel Adelino, Kristopher Gerardi, and Paul S. Willen. All rights reserved. Short sections of text, not to exceed two paragraphs, may be quoted without explicit permission provided that full credit, including $\odot$ notice, is given to the source. 
Why Don't Lenders Renegotiate More Home Mortgages?

Redefaults, Self-Cures and Securitization

Manuel Adelino, Kristopher Gerardi, and Paul S. Willen

NBER Working Paper No. 15159

July 2009

JEL No. D11,D12,G21

\begin{abstract}
$\underline{\text { ABSTRACT }}$
We document the fact that servicers have been reluctant to renegotiate mortgages since the foreclosure crisis started in 2007, having performed payment reducing modifications on only about 3 percent of seriously delinquent loans. We show that this reluctance does not result from securization: servicers renegotiate similarly small fractions of loans that they hold in their portfolios. Our results are robust to different definitions of renegotiation, including the one most likely to be affected by securitization, and to different definitions of delinquency. Our results are strongest in subsamples in which unobserved heterogeneity between portfolio and securitized loans is likely to be small and for subprime loans. We use a theoretical model to show that redefault risk, the possibility that a borrower will still default despite costly renegotiation, and self-cure risk, the possibility that a seriously delinquent borrower will become current without renegotiation, make renegotiation unattractive to investors.

Manuel Adelino

MIT Sloan

50 Memorial Dr, E52-458

Cambridge, MA 02138

madelino@mit.edu

Kristopher Gerardi

Federal Reserve Bank of Atlanta

1000 Peachtree St. NE

Atlanta, GA 30309

kristopher.gerardi@atl.frb.org

Paul S. Willen

Research Department

Federal Reserve Bank of Boston

P.O. Box 55882

Boston, MA 02210

and NBER

willen968@yahoo.com
\end{abstract}




\section{Introduction}

Many commentators have attributed the severity of the foreclosure crisis in the United States in the 2007-2009 period to the unwillingness of lenders to renegotiate mortgages, and, as a consequence, have placed renegotiation at the heart of the policy debate. Every major policy action to date has involved encouraging lenders, in one way or another, to renegotiate loan terms in order to reduce borrower debt loads. According to the Treasury-sponsored HopeNow initiative, in December of 2007 lenders were expected to prevent adjustable-rate mortgages from increasing to higher rates at the first reset of the mortgage. "Hope For Homeowners," enacted by Congress in July of 2008, envisioned that lenders would write off a substantial portion of the principal balance of mortgages for financially distressed households. ${ }^{2}$ The Obama Adminstration's Making Home Affordable Plan, announced in February of 2009, provided financial incentives to servicers to renegotiate loans on the condition that the lenders reduce the interest rate for a significant period of time. ${ }^{3}$

The appeal of renegotiation to policy makers is simple to understand. If a lender makes a concession to a borrower by, for example, reducing the principal balance on the loan, it can prevent a foreclosure. This is clearly a good outcome for the borrower, and possibly good for society as well. But the key to the appeal of renegotiation is the belief that it can also benefit the lender, as the lender loses money only if the reduction in the value of the loan exceeds the loss the lender would sustain in a foreclosure. In short, according to proponents, renegotiation of home mortgages is a type of public policy holy grail, in that it helps both borrowers and lenders at little or no cost to the government. ${ }^{4}$

In this paper, we explore the renegotiation of home mortgages using a dataset from Lender Processing Services (LPS), a large, detailed sample of residential mortgages. Our primary empirical analysis involves following borrowers over the year subsequent to their first serious delinquency and counting the frequency of renegotiation. ${ }^{5}$ Measuring renegotiation in the LPS data is a challenge because there is no field in the data that identifies whether or not a servicer has changed the terms of, or "modified," the loan. We overcome this difficulty by developing an algorithm to identify modifications that we validate on an unrelated dataset that includes a modification flag.

We explore several different definitions of renegotiation in the data. Our first definition of "renegotiation" is concessionary modifications that serve to reduce a borrower's monthly

\footnotetext{
${ }^{1}$ Edmund L. Andrews, In Mortgage Plan, Lenders Set Terms, New York Times, Dec. 7, 2007.

2 "Bush Signs Wide-Ranging Housing Bill Into Law," Wall Street Journal, July 31, 2008.

${ }^{3}$ See $" \$ 275$ Billion Plan Seeks To Address Crisis In Housing," New York Times, Feb. 18, 2009.

${ }^{4}$ See this discussion in Congressional Oversight Panel (2009), Zingales (2008), and Geanakoplos and Koniak (2008), as examples.

${ }^{5}$ Until 2008, the dataset was known as McDash.
} 
payment. These may be reductions in the principal balance or interest rate, extensions of the term, or combinations of all three. This definition of renegotiation is a key focus of our analysis because there is a consensus among many market observers that concessionary modifications are the most, or possibly the only, effective way of preventing foreclosures. As the Congressional Oversight Panel (COP) for the Troubled Asset Recovery Program (TARP) has written, "Any foreclosure mitigation plan must be based on a method of modifying or refinancing distressed mortgages into affordable ones. Clear and sustainable affordability targets achieved through interest rate reductions, principal write-downs, and/or term extensions should be a central component of foreclosure mitigation." 6

Because the pooling and servicing agreements (PSAs), which govern the conduct of servicers when loans are securitized, often place limits on the number of modifications a servicer can perform, we broaden our definition of renegotiation to include any modification, regardless of whether it lowers the borrower's payment. Modifications are often thought to always involve concessions to the borrower, but many, and in some subsets most, modifications involve the capitalization of arrears into the balance of the loan, and thus lead to increased payments.

Finally, we attempt to include in our definition of renegotiation the transactions whereby lenders allow borrowers to extinguish their liabilities by repaying less than the outstanding balance of the loan. These transactions are known as short payoffs, short sales, or deeds-inlieu of foreclosure, depending on the structure. We measure this component of renegotiation by counting the number of seriously delinquent loans that the servicer reports as "paid off."

No matter which definition of renegotiation we use, one message is quite clear: lenders rarely renegotiate. Fewer than 3 percent of the seriously delinquent borrowers in our sample received a concessionary modification in the year following the first serious delinquency. More borrowers received modifications under our broader definition, but the total still accounted for fewer than 8 percent of the seriously delinquent borrowers. And finally, fewer than 5 percent of all of our troubled borrowers repaid their mortgages, putting an upper bound on the number who could have repaid less than the principal balance of the loan. These numbers are small both in absolute terms, and relative to the approximately half of the sample for whom foreclosure proceedings were initiated, and the nearly 30 percent for whom they were also completed.

We next turn to the question of why renegotiation is so rare. If the logic described in the second paragraph is correct, lenders should find renegotiation attractive, even in the

\footnotetext{
${ }^{6}$ See the Congressional Oversight Panel (2009). This view is widely held and is the main focus of the Administration's Making Home Affordable foreclosure prevention plan was to encourage servicers to modify loans to reduce monthly payments to 31 percent of income.
} 
absence of government prodding. Yet, we observe very little renegotiation in the data. We address this apparent paradox.

The leading explanation attributes the reluctance of lenders to renegotiate to the process of securitization.

The complex webs that securitization weaves can be a trap and leave no one, not even those who own the loans, able effectively to save borrowers from foreclosure. With the loan sliced and tranched into so many separate interests, the different claimants with their antagonistic rights may find it difficult to provide borrowers with the necessary loan modifications, whether they want to or not. In the tranche warfare of securitization, unnecessary foreclosures are the collateral damage. (Eggert 2007)

More precise institutional evidence appears to confirm the role of securitization in impeding renegotiation. As mentioned in more detail below, PSAs do sometimes place global limits on the number of modifications a servicer can perform for a particular pool of mortgages. In addition, the rules by which servicers are reimbursed for expenses may provide a perverse incentive to foreclose rather than modify. Furthermore, because servicers do not internalize the losses on a securitized loan, they may not behave optimally. Another issue is the possibility that those investors whose claims are adversely affected by modification will take legal action. Finally, historically, SEC rules have stated that contacting a borrower who is fewer than 60-days delinquent constitutes an ongoing relationship with the borrower and jeopardizes the off-balance sheet status of the loan.

But some market observers express doubts about the renegotiation-limiting role of securitization. Hunt (2009) conducted an exhaustive review of a sample of PSAs and concluded, "it appears that large-scale modification programs may be undertaken without violating the plain terms of PSAs in most cases." Although some servicers have expressed concern about lawsuits, of the more than 800 lawsuits filed by investors in subprime mortgages through the end of 2008, not one involved the right of a servicer to modify a loan. ${ }^{7}$ Even the Congressional Oversight Panel (2009), which did view securitization as a problem in general, conceded, "The specific dynamics of servicer incentives are not well understood." Finally, the SEC ruled in 2008 that if default was "reasonably forseeable," then contact with a borrower prior to 60-day delinquency would not affect the accounting status of the loan.

Our empirical analysis provides strong evidence against the role of securitization in preventing renegotiation. The LPS dataset includes loans that are serviced for private securitization trusts that are not sponsored by any of the government sponsored enterprises

\footnotetext{
${ }^{7}$ Navigant report, Congressional Oversight Panel (2009).
} 
(GSEs), so-called "private-label" loans, which are subject to all of the contract frictions described above. It also includes loans owned by servicers, so-called "portfolio" loans, which are immune to such problems. We compare renegotiation rates, controlling for observable characteristics of the loans. For our narrowest definition of renegotiation, payment-reducing modification, we find that the differences in the likelihood of renegotiation in the 12 months subsequent to the first 60-day delinquency between the two types of loans is neither economically nor statistically significant. When we consider the broader definition that includes any modification at all, which, as we mentioned above, we would expect to be most affected by securitization, the data even more strongly reject the role of securitization in preventing renegotiation. We also find that servicers are more likely to peform modifications, broadly defined, and to allow the borrower to prepay on a private-label loan than on a portfolio loan.

Our results are highly robust. One potential problem with the data is that there is unobserved heterogeneity in the characteristics of portfolio and private-label loans. To address this, we exploit subsets of the LPS data, in which servicers provide an exceptional amount of information about borrowers. When we exclude observations where the servicer failed to report whether the borrower fully documented income at origination, or what the debt-to-income ratio was at origination, our results become even stronger. When we focus only on loans for which the borrower fully documented income, we obtain results that are broadly consistent or, in some cases, stronger than the results for the full sample. Finally, we limit our sample to only subprime loans (as defined in LPS). These loans comprise only 7 percent of the LPS data, but they account for more than 40 percent of all serious delinquencies and almost 50 percent of the modifications that we identify in the data. The results that we obtain for the subprime sample are also consistent with our results for the full sample.

Another potential issue with our focus on 60-day delinquent loans is that portfolio lenders can contact borrowers at any time, whereas some securitization agreements forbid lenders from contacting borrowers until they are at least 60 days delinquent (two missed payments). When we shift our focus to 30-day delinquent borrowers (one missed payment), our results continue to show no meaningful difference between renegotiation of private-label and portfolio loans.

One other possibility is that our algorithm for identifying modifications is somehow missing a class of loss-mitigation actions taken by servicers. Forbearance agreements and repayment plans, for example, would not necessarily show up in our data. However, neither of these actions constitutes renegotiation in any classic sense, because the lender still expects the borrower to repay in full, including interest on any delayed payment. In addition, unlike 
modifications, PSAs never place any limits on the use of forbearance agreements or repayment plans, so, a priori, we would have less reason to expect a difference in their use across private-label and portfolio loans. Finally, most successful forbearance agreements conclude with a modification to allow the borrower to repay the arrears incurred in forbearance. With all of that said, we test the proposition that servicers engage in other loss mitigation actions by looking at the "cure rate." This is the percentage of loans that transition to current status after becoming 60-days delinquent. We find that in the full sample, private-label loans are less likely to cure, but that the gap, although statistically significant, is small correcting for observable characteristics, we estimate a cure rate of around 30 percent for the typical portfolio loan and a cure rate of about 2 percentage points less for an otherwise equivalent private-label loan. However, for the subprime subsample, the subsample with information about documentation and debt-to-income (DTI) status, and the sample of fully documented loans, we find that private-label loans are significantly more likely to cure.

The policy debate has focused exclusively on the ways securitization impedes renegotiation and implicitly assumes that portfolio lenders face no institutional impediments, but this is not realistic. Portfolio lenders complain about accounting rules, including the need to identify modifications, even when the borrowers are current prior to the modification, as "troubled debt restructurings," which leads to reduction of the amount of Tier II capital and increased scrutiny from investors and cumbersome accounting requirements. The shortage of qualified staff, an oft-heard complaint from borrowers seeking renegotiation, affects servicers of portfolio loans and private label loans equally. Finally, the interests of the managers of a loan portfolio are not necessarily any more likely to be aligned with their investors than are the interests of the trustees of a mortgage pool; many have attributed the catastrophic failures of financial institutions like AIG in 2008 to misaligned incentives of managers and shareholders.

Our results are consistent with the hypothesis that securitization does impede renegotiation but that a different set of impediments leads to similar problems with portfolio loans and generates our finding that there is no difference. However, the small differences would represent a remarkable coincidence. ${ }^{8}$ More importantly, the low overall levels of renegotiation mean that even if contract frictions cut the overall number of concessionary modifications in half, 94 percent of seriously delinquent borrowers would still fail to receive a concessionary modification. So the puzzle remains why so few loans are renegotiated.

If contract frictions are not a significant problem, then what is the explanation for

${ }^{8}$ Yet another possible explanation is that equal treatment provisions in PSAs force servicers to modify similar numbers of portfolio and private-label loans and that servicers are reluctant to modify portfolio loans in spite of the fact that they internalize the benefits because they must then modify private label loans for which they don't. 
why lenders do not renegotiate with delinquent borrowers more often? We argue for a very mundane explanation: lenders expect to recover more from foreclosure than from a modified loan. This may seem surprising, given the large losses lenders typically incur in foreclosure, which include both the difference between the value of the loan and the collateral, and the substantial legal expenses associated with the conveyance. The problem is that renegotiation exposes lenders to two types of risks that can dramatically increase its cost. The first is what we will call "self-cure" risk. As we mentioned above, more than 30 percent of seriously delinquent borrowers "cure" without receiving a modification; if taken at face value, this means that, in expectation, 30 percent of the money spent on a given modification is wasted. The second cost comes from borrowers who redefault; our results show that a large fraction of borrowers who receive modifications end up back in serious delinquency within six months. For them, the lender has simply postponed foreclosure; in a world with rapidly falling house prices, the lender will now recover even less in foreclosure. In addition, a borrower who faces a high likelihood of eventually losing the home will do little or nothing to maintain the house or may even contribute to its deterioration, again reducing the expected recovery by the lender.

In Section 4 of the paper, we formalize the basic intuition of the investor renegotiation decision, with a simple model. We show that higher cure rates, higher redefault rates, higher expectations of house price depreciation, and a higher discount rate all make renegotiation less attractive to the investor. Thus, one cannot evaluate a modification by simply comparing the reduction in the interest rate on the loan or in the principal balance with the expected loss in foreclosure. One must take into account both the redefault and the self-cure risks, something that most proponents of modification fail to do. ${ }^{9}$

To our knowledge, this paper is the first to estimate directly the likelihood of renegotiation of private-label and portfolio-held loans. Piskorski, Seru, and Vig (2009) address the question of the effects of securitization on renegotiation, but rather than directly identifying renegotiation, they run "black-box" foreclosure regressions using LPS data and argue that observed differences in foreclosure rates imply differences in renegotiation activity. Our results contradict this interpretation. For renegotiation to explain the differences in foreclosure rates, there would have to be large errors in our algorithm for identifying renegotiation, and those errors would have to be significantly biased toward portfolio loans, a possibility that is particularly problematic given that the renegotiations we focus on are precisely the type that PSAs supposedly prevent. In addition, most of the loan histories in the LPS

\footnotetext{
${ }^{9}$ Many proponents of aggressive modification take into account redefault risk, and the MHA plan did address it by providing some insurance against further house price declines to investors who modified loans. However, none of the main proponents ever mentions self-cure risk, even though it is well-known in the industry, see: http://www.calculatedriskblog.com/2008/09/loan-modifications-anecdotes-and-data.html.
} 
sample are right-censored, meaning that the borrowers have neither lost their homes nor paid off their mortgages when the data end, making it impossible to equate the absence of a foreclosure with successful renegotiation. By contrast, a "cure" is a necessary condition for renegotiation, and thus the differences we report in cure rates across portfolio and private-label loans that are neither large nor of consistent sign contradict the claim that securitization is a major obstacle to renegotiation.

The implications of our research for policy are three-fold. First, "safe harbor" provisions, which shelter servicers from investor lawsuits, are unlikely to affect the number of modifications and should have little effect. Second, and more broadly, the number of "preventable foreclosures" may be far fewer than many believe.

Finally, we point out that while our model shows why investors may not want to perform modifications, that does not necessarily imply that modifications may not be socially optimal. One key input to our theoretical model is the discount rate, and it is possible that investors, especially in a time when liquidity is highly valued, may be less patient than society as a whole, and therefore foreclose when society would prefer renegotiation. Large financial incentives to investors or even to borrowers to continue payment could mitigate this problem.

\subsection{Related Literature and Existing Evidence}

Our research draws on existing literature in several different fields. First, there has been substantial interest in the question of renegotiation of home mortgages among real estate economists, both prior to, and as a result of the current crisis. Riddiough and Wyatt (1994a), Riddiough and Wyatt (1994b), and Ambrose and Capone (1996) addressed informational issues that inhibit efficient renegotiation. We draw extensively on this research in Section 4. Springer and Waller (1993), in an early example, explores patterns in the use of forbearance as a loss mitigation tool. Capone (1996) and Cutts and Green (2005) both discuss the institutional issues, with the former study providing historical evidence and focusing on issues in the mid-1990s, and the latter study discussing innovations since then.

The start of the subprime crisis in 2007 led to a resurgence of interest in the topic among real estate economists and aroused new interest from other fields, in particular, the field of law. In real estate, Quercia, Ding, and Ratcliffe (2009), Cutts and Merrill (2008), Stegman, Quercia, Ratcliffe, Ding, Davis, Li, Ernst, Aurand, and Van Zandt (2007), and Mason (2007), all discuss issues with contemporary loss mitigation approaches. Legal researchers, White (2008) and White (2009), for example, have addressed empirical questions about the frequency and characteristics of loan modifications, closely related to the analysis in this 
paper. In addition, they have also looked at issues related to the restrictions imposed by contracts (Hunt 2009 and Gelpern and Levitin 2009) and the interactions among foreclosure, renegotiation, and personal bankruptcy (Levitin 2009a and Levitin 2009b).

More broadly, real estate economists have explored the factors that lead delinquent mortgages to transition to foreclosure or to cure, one of which is renegotiation. Pre-crisis papers include Ambrose and Capone (1998), Ambrose, Buttimer Jr, and Capone (1997), Ambrose and Capone (2000), Lauria, Baxter, and Bordelon (2004), Danis and PenningtonCross (2005), Pennington-Cross (2009), and Pennington-Cross and Ho (2006). Mulherin and Muller (1987) discusses conflicts between mortgage insurers and owners that may lead servicers to induce or postpone foreclosure inefficiently. In light of the crisis, Piskorski, Seru, and Vig (2009) and Cordell, Dynan, Lehnert, Liang, and Mauskopf (2008a) have revisited the question.

The issue of dispersed ownership and debt renegotiation has received a fair amount of attention in the corporate finance literature. Gan and Mayer (2006), for example, focus on commercial mortgages, and find that servicers delay liquidation of delinquent mortgages when they are also the holders of the equity tranche of the deal. This suggests that participating in the losses due to liquidation may alleviate some of the agency problems posed by the separation of ownership and servicing pointed out before. However, it may also lead to conflicts of interest between holders of different tranches. In their setting, Gan and Mayer (2006) find that the servicers' behavior is consistent with asset substitution, as servicers seek to benefit from the option-like payoff of their position. Also, the contractual restrictions imposed by PSAs (discussed above) and standard economic arguments on the effects of dispersed ownership of debt (as in Bolton and Scharfstein 1996 and Asquith, Gertner, and Scharfstein 1994) further reduce the incentives of servicers to modify mortgages.

\section{Data}

We use a dataset constructed by LPS. This is a loan-level dataset that covers approximately 60 percent of the U.S. mortgage market and contains detailed information on the characteristics of both purchase-money mortgages and mortgages used to refinance existing debt. ${ }^{10}$ This dataset is especially useful in the context of this paper, as it includes both securitized mortgages and loans held in portfolio. ${ }^{11}$ The LPS data specifically denote whether a mort-

\footnotetext{
${ }^{10}$ We use a 10 percent random sample of the LPS data when estimating all of our empirical models. The dataset is simply too big to use in its entirety from a computational standpoint. However, we have checked the robustness of our results to using different sample sizes, and we do not find substantial differences.

${ }^{11}$ For a more detailed discussion of the LPS data, we direct the reader to Foote, Gerardi, Goette, and Willen (2009).
} 
gage is held in portfolio, or securitized by a non-agency, private institution. ${ }^{12}$ If institutional constraints are restricting the modification process for private-label, securitized loans, we would expect to see relatively few modifications among them, as compared to portfolio loans. Unfortunately, our LPS sample does not include direct information regarding loan modifications. ${ }^{13}$ However, LPS does provide monthly updates to loan terms, so it is possible to identify loan modifications indirectly (and imperfectly). Table 1 shows two examples of modifications in the data. In the first example, the servicer cuts the interest rate, capitalizes arrears into the balance of the loan, and extends the term of the loan to 40 years. In the second example, the servicer just capitalizes arrears into the balance of the loan. In both cases the loan is reported as "current" after the modification, whereas before it was $90+$ days delinquent.

We denote a loan as being modified if there is a change in its terms that was not stipulated by the initial terms of the contract. Such modifications include interest-rate reductions, principal-balance reductions, and term extensions. We can also identify principal-balance and mortgage-payment increases that reflect the addition of arrears into the balance of a loan. ${ }^{14}$ We spell out our algorithm for identifying modifications in more detail in Appendix A.

There are two potential mistakes we can make in this exercise. First, we may falsely identify modifications ("false positives") because of measurement error in the data (for example, a mistake in the updated balance or interest rate) or some endogenous behavior on the part of the borrower (for example, a borrower making extra principal payments). Second, we could miss modifications ("false negatives") because our algorithm for finding modifications is incomplete. In order to test our algorithm, we use data from the Columbia files put together by Wells Fargo's CTSLink service. This dataset includes a similar set of variables to those in the LPS dataset (on performace of the loans and characteristics of the borrower at origination) but is limited to private-label loans. These files do include,

${ }^{12}$ The LPS data also denote when a loan is securitized by a GSE (Government Sponsored Enterprise) such as Freddie Mac or Fannie Mae. We eliminate this class of loans, since the GSEs hold all credit risk, and thus are not subject to any modification restrictions.

${ }^{13}$ In a recent report, the Office of Thrift Supervision (OTS), in collaboration with the Office of the Comptroller of Currency (OCC), used data from LPS to analyze the outcomes of recent mortgage modification programs (OCC and OTS Mortgage Metrics Report, Third Quarter 2008). In this report, they had access to supplementary data from servicers that include the identification of loans in the LPS data that had been modified. We have not been able to obtain access to this data.

${ }^{14}$ One of the major types of loan modifications that we are largely unable to identify are interest rate freezes for subprime ARMs, which reset after two or three years. However, the reason that we cannot identify those freezes is because many are not binding; the fully-indexed rate is lower than the initial rate. These modifications will have no major effect on the current terms of the mortgage, so we do not view this as a major drawback. 
however, explicit flags for modifications. This allows us to use the same algorithm described in Appendix A and compare the modifications we identify to the "true" modifications. Results are reported in Table 2. Overall our algorithm performs well, with 17 percent false negatives (that is, we do not identify around 17 percent of the "true" modifications) and around the same percentage of false positives (that is, approximately 17 percent of the modifications we identify are not flagged as modifications on the CTSLink data). By type of modification, our algorithm performs best for principal reductions, term increases, and fixed-rate mortgage reductions, and comparatively worse for ARM rate reductions and for principal increases.

\subsection{Summary Statistics from the Data}

Table 3 reports the number of modifications performed each quarter from the first quarter of 2007 through the final quarter of 2008, disaggregated by the type of modification. Each of the numbers is a multiple of 10 because we used a 10 percent random sample and scaled up the numbers we found. The first column of Table 3 simply reports the total number of loan modifications made. Not surprisingly, modifications have become more common as the housing market has weakened. There appear to be more than 7-8 times as many modifications performed in the fourth quarter of 2008 as in the first quarter of 2007. In addition to the rapid growth in loan modifications, the composition of modifications has changed over time. This can be seen in the remaining columns of Table 3, which list the incidence of modifications of different types. ${ }^{15}$

An interesting finding is that most modifications entailed increases in the principal balance of a mortgage. Such increases are likely due to the addition of arrears to the outstanding mortgage balance for delinquent borrowers, and these often increase the monthly mortgage payment by a nontrivial amount. While the absolute numbers of balance-increasing modifications are still rising, they are falling as a percentage of total modifications. In the last few quarters, interest-rate reductions, which necessarily involve a decrease in the monthly mortgage payment, have become more frequent, rising to more than 26 percent of all modifications performed in 2008:Q4. Table 3 provides further information regarding the behavior of monthly mortgage payments for loans that have undergone a modification. There are several notable patterns in this table. First, as of 2008:Q4, modifications that involved payment decreases were more common than those that involved payment increases. Furthermore, the

\footnotetext{
${ }^{15}$ In many cases a mortgage will experience multiple types of modifications at the same time. For example, we see cases in the data in which the interest rate is decreased and at the same time the term of the loan is extended. Thus, the percentages in Table 3 are not calculated with respect to the number of loans modified, but rather with respect to the number of modifications performed.
} 
average and median magnitude of payment decreases has recently increased in our sample. From 2007:Q1 to 2008:Q2, the median payment decrease ranged from approximately 10 percent to 14 percent, but then increased to approximately 20 percent and 22 percent in 2008:Q3 and 2008:Q4, respectively. Based on the logic from our simple framework above, it is likely that these will have more success than modifications involving increases in the payment and/or balance.

Another interesting observation from Table 3 is that the incidence of principal reductions is quite low in our data. This is likely due to two factors. First, the LPS dataset underrepresents the subprime mortgage market. ${ }^{16}$ A few servicers that focus almost exclusively on subprime mortgages have recently begun modification programs that involve principal reduction. ${ }^{17}$ In addition, from a theoretical perspective, principal reduction plans suffer from the severe incomplete-information problem noted earlier. Balance reductions are appealing to both borrowers in danger of default and those who are not. In a recent paper, we argued that to avoid such moral hazard concerns, lenders have a strong incentive to only provide modifications to those borrowers who are most likely to default. ${ }^{18}$ Table 3 contains summary statistics regarding the characteristics at origination of both the sample of modified mortgages and the sample of all loans in the LPS dataset. The patterns that emerge from the table are consistent with such an argument. We discuss this point in more detail below. The sample of modified mortgages is characterized by substantially lower credit scores, higher loan-to-value (ltv) ratios, and slightly higher debt-to-income ratios. The discrepancy in ltv ratios may be underestimated, as the percentage of mortgages with an ltv ratio of exactly 80 percent is significantly higher in the modification sample than in the full sample. As we argued above, this likely implies a larger fraction of highly leveraged loans, for which the second liens are not observable in the data. In addition, the modification sample includes a higher fraction of mortgages with non-traditional amortization schedules, such as interestonly loans, option ARMS, hybrid ARMs, and subprime loans.

In Table 4 we compare the size of payment decrease and payment increase modifications for loans held in private-label trusts and loans held in portfolio. The results are somewhat mixed, as the size (as a percentage of the original payment) of the median payment decrease due to modification is larger for private-label loans in the first three quarters of 2008, but smaller in the final quarter. We see a similar pattern for the median payment increase due

\footnotetext{
${ }^{16}$ The majority of subprime mortgages are securitized by non-agency firms, and the LPS dataset includes approximately 35 percent of mortgages securitized by non-agency corporations.

${ }^{17}$ According to an October report by Credit Suisse, Ocwen Loan Servicing, LLC and Litton Loan Servicing LP were the only subprime servicers that had performed a nontrivial number of principal reduction modifications. Neither of these servicers contributes to the LPS dataset.

${ }^{18}$ See Foote, Gerardi, and Willen (2008) for a more detailed discussion.
} 
to modification, while the differences are small for the mean and median payment increase.

\section{Differences in Modification Behavior}

In this section, we directly address the question of whether the incidence of modification is impeded by the process of securitization. We show evidence that private-label loans and portfolio loans perform similarly, both unconditionally and when observable differences between securitized and portfolio-held loans are controlled for, using both a logit model with a 12-month horizon and a Cox proportional hazard model that takes into account the problem of right censoring in the data.

To make sure that our results are robust to the type of modification performed, we use several different definitions of modification in this section. Our first measure is the number of concessionary modifications, which we define as reductions in the interest rate, reductions in the principal balance, extensions of the term, or combinations of all three. Any or a combination of these serves to reduce a borrower's monthly mortgage payment. We use this as our primary definition of modification in our analysis, as there is a consensus among most market observers that concessionary modifications are the most, or perhaps the only, effective way of preventing foreclosures. Because pooling and servicing agreements, which govern the conduct of servicers when loans are securitized, often limit modifications that change any of the contract terms (not just those that result in payment decreases), we broaden our definition of renegotiation to include any modification, regardless of whether it lowers the borrower's payment. As we discussed above, many, and in some subsets, most modifications, involve the capitalization of arrears into the balance of the loan and thus lead to increased payments. Finally, we attempt to include in our measure of renegotiation the number of times that lenders allow borrowers to extinguish their liabilities by repaying less than the outstanding balance of the loan. These transactions are known as short payoffs, short sales, or deeds-in-lieu of foreclosure, depending on the structure. We do this by counting the number of seriously delinquent loans that the servicer reports as paid off, and including these observations in our definition of modification.

Before turning to the regressions, however, it is instructive to look at the unconditional frequencies of modifications in the data. Panel A of Table 5 shows the unconditional frequencies for each type of investor. The first takeaway from the table is the extremely low percentages of modifications for both types of mortgages. Only 3 percent of 60-day delinquent loans received concessionary modifications in the 12 months following the first serious delinquency, and only 8.5 percent of the delinquent loans received any type of modification in the same period. These are extremely low levels of modifications, and they suggest that 
even if there are contract frictions that are preventing modifications in securitized trusts, the economic effects are small. The second takeaway from the table is that the unconditional differences between portfolio loans and private-label loans are very small in absolute terms. There is a difference of approximately 0.6 percentage points and 0.3 percentage points for concessionary modifications and all modifications, respectively. These are very small differences, and they suggest that contract frictions do not play an important role in inhibiting the renegotiation process for loans in securitized trusts. However, these are unconditional statistics, and it is possible that once observable differences in the characteristics of each type of loan and borrower are accounted for, the results may change. ${ }^{19}$ Thus, we now estimate differences in modification behavior while controlling for observable loan and borrower characteristics. These characteristics include the contract interest rate at origination; the credit score of the borrower at origination; the loan-to-value ratio of the mortgage (not including second or third liens) at origination ${ }^{20}$; the logarithm of the nominal dollar amount of loan; an indicator of whether the purpose of the loan was a refinance of a previous mortgage or a home purchase; an indicator of whether the loan was considered to be subprime ${ }^{21}$; a measure of the amount of equity in the property at the time of delinquency, specified as a percentage of the original loan balance and updated by state-level house price indexes calculated by the Federal Housing Finance Agency (FHFA) ${ }^{22}$ (and an indicator for a borrower who is in a position of negative equity at the time of delinquency, where the value of the mortgage exceeds the value of the home); and the unemployment rate of the county in which the borrower resides, calculated by the Burea of Labor Services (BLS). ${ }^{23}$ We also include, but do not show because of space considerations, a set of cohort dummies that control for the quarter when the mortgage was originated, information regarding the amortization schedule of the mortgage (interest-only or negative amortization, including mortgages commonly referred to as option ARMs), an indicator for whether the size of the mortgage is greater than the GSE conforming loan limits, an indicator for whether the

\footnotetext{
${ }^{19}$ For example, if private-label loans are significantly riskier, and thus better candidates for modification on average, then the unconditional difference will significantly understate things.

${ }^{20}$ Because of the lack of information on second liens in the LPS data and the prevalence of second mortgages as a way to avoid paying mortgage insurance, we include an indicator variable if the ltv ratio is exactly equal to 80 percent. These are the borrowers who likely took out second mortgages, as the requirement for mortgage insurance occurs at ltv ratios above 80 percent. Our experience with other, more complete datasets also confirms that many of these borrowers are likely to have second mortgages that bring the cumulative ltv ratio up to 100 percent.

${ }^{21}$ This definition of subprime comes from the mortgage servicers that contribute to the LPS dataset.

${ }^{22}$ House prices are measured at the state level using the FHFA index. We also tried using Case-Shiller metropolitan area house price indexes and found no substantive differences. We chose to use the OFHEO prices for our primary specifications because of their greater sample coverage.

${ }^{23}$ Equity and periods of unemployment are very important determinants of a borrower's decision to default, and thus should also be important factors in the modification decision.
} 
house is a primary residence, an indicator for adjustable rate mortgages that contain a reset provision (so-called "hybrid ARMs"), and, finally, an indicator for a borrower who does not use the corresponding property as a principal residence (this includes both properties used strictly for investment purposes, and vacation homes).

\subsection{Canonical Specification Results}

Panel B of Table 5 displays the estimated marginal effects from a set of logit models for the three different types of modification definitions. The dependent variable is 1 if a 60 -day deliquent loan is modified at any point in the 12 months following the first delinquency. The first column considers payment-reducing (concessionary) modifications, the second column includes both payment-reducing and payment-increasing modifications, and the third column contains all modifications considered before, as well as prepayments. In all regressions, the group of portfolio-held loans is omitted from the estimation and is thus assumed to be the reference group. We cluster the standard errors at the zip code level to account for the fact that loans in the same geographical area are likely to suffer correlated (unobserved) shocks.

According to the estimates in the first column, private-label loans were approximately 0.3 percentage points less likely to receive concessionary modifications than loans held in portfolio. This estimate is economically small but statistically significant at the 10 percent level. When we consider all modifications the point estimate flips sign and becomes 0.2 percentage points (statistically insignificant), while for the third specification, private-label loans were actually 0.9 percentage points more likely to receive concessionary modifications (statistically significant). As discussed above, all of these specifications include a number of additional loan characteristics that are important in the underwriting process and, thus, likely to play an important role in the modification decision. The first observation to make regarding the results reported in Panel B is that the difference between the incidence of modification for portfolio-held loans and private-label loans becomes even smaller when these variables are controlled for in the estimation. The results also imply that loans with higher credit scores were modified less, loans with higher ltv ratios were modified less, larger loans were modified more, and loans with more equity at the time of delinquency were modified less. We find a sizeable difference in terms of the frequency of modification for both refinances and subprime loans. Conditional on being 60-days delinquent, subprime loans were modified about 2 percentage points more than prime loans. We estimate a model separately for subprime loans in Table 6 .

Censoring is an important issue for any sample of mortgages, as there are currently 
many delinquent loans that are, or will soon be, good candidates for modification, as the housing market continues to decline. For this reason, we estimate a Cox proportional hazard model of the transition from serious delinquency to modification. The Cox model is very common in the survival analysis literature, and it has the advantage of being both flexible in terms of functional form considerations, as the baseline hazard function can be treated as an incidental parameter, and easy to estimate in terms of computational considerations. The results, expressed as hazard ratios, are reported in Panel C. A hazard ratio less than 1 indicates that private-label loans were less likely to receive a modification compared to portfolio loans, while a ratio greater than 1 signifies the opposite. The estimates are consistent with what we report for the logits in the previous panel. Private-label loans were less likely to receive concessionary modifications, but this coefficient estimate is statistically insignificant. For the our other two modification definitions the sign flips, but again the result is not statistically significant. All three specifications include the same covariates that were included in the logit models.

\subsection{Subsample Results}

Table 6 contains further logit estimation results for various subsamples of interest to see if there are different probabilities than in the full sample. Since the subprime indicator seems to be such a powerful predictor of modification conditional on serious delinquency in Table 5 , we report the estimated marginal effects for only the sample of subprime loans in the second column of Table 6. The subprime sample also has the advantage that the agencies (Fannie Mae and Freddie Mac) were unlikely to be the marginal investor for this type of loans, so it is less likely that the portfolio and private-label samples differ significantly on unobservable characteristics. In the third column, we report results from the sample of LPS mortgages for which the borrower had a FICO score of less than 620, since automated underwriting systems generally instruct lenders to engage in increased scrutiny for such loans because of increased default risk. In the fourth and fifth columns, we focus on samples of loans that we believe contain the most information regarding the borrowers, in order to try to minimize the amount of unobservable heterogeneity that could potentially be biasing the results. In the fourth column, we focus on the sample of loans for which both the DTI ratio and the documentation status contain non-missing values, while the fifth column contains results for only the loans that were fully documented (in terms of income and assets) at origination. Panel A contains both unconditional means and estimated marginal effects for concessionary modifications, while Panel B contains results for the broader definition that also includes non-concessionary modifications. 
The results are largely consistent with those contained in Table 5. We redisplay the results from the full sample in the first column of Table 6 for ease of comparison. The difference in modification frequency between private-label and portfolio-held, subprime mortgages for 60-day delinquent loans is small, and not statistically different from zero for both definitions of modification. Using a FICO cutoff of 620 as an alternative definition of subprime does not seem to make much difference. The unconditional means are smaller (for both types of loans) compared to the LPS subprime sample, as the LPS definition includes most of the loans with a FICO less than 620, but also some loans with higher associated FICOs. However, the marginal effects of private-label loans estimated from the logit models are quite similar to those from the LPS subprime sample, as they are economically small, and not statistically significant. Finally, we also find small and largely insignificant results for the last two subsamples, displayed in the fourth and fifth columns of Table 6. Although, it is worth pointing out that we do find a statistically significant, positive estimate of private-label loans for the broad definition of modification (Panel B).

\subsection{Alternative Delinquency Definition}

As an additional robustness check, we broaden our definition of delinquency and focus on modifications performed on loans subsequent to their first 30-day delinquency, which corresponds to one missed mortgage payment. While waiting until a borrower becomes seriously delinquent (defined as 60-days) to renegotiate is common practice in the servicing industry, there are no direct contractual stipulations (to our knowledge) that restrict a servicer from modifying the loan of a borrower who is 30-days delinquent. Thus, in Table 7 we repeat our analysis of Tables 5 and 6 , but condition on 30-days delinquency rather than 60-days. The table contains three panels of estimation results, one for each of our modification definitions, and all of the subsamples described considered in Table 6. The unconditional means, logit marginal effects, and Cox hazard ratios are all reported for each combination of subsample and modification definition.

The results are very similar to those from the analysis of 60-day delinquent loans. According to the full sample and subprime sample logit models, portfolio loans received slightly more concessionary modifications, and the differences ( 0.3 and 0.5 percentage points respectively) are statistically significant at conventional levels. However, according to the subprime sample and full documentation sample Cox models, private-label loans actually received more concessionary modifications, although those differences are also small. ${ }^{24}$ The results

\footnotetext{
${ }^{24}$ The logit marginal effects correspond to percentage point differences, while the Cox hazard ratios correspond to percent differences. If one expresses the logit marginal effects as a percent change of the unconditional means, those percent changes are very similar in magnitude to the Cox results.
} 
for our second modification definition are similar, although we find more evidence of statistically significant, positive differences between the incidence of portfolio and private-level modifications. The samples of portfolio loans with non-missing information for DTI and documentation status were modified more often than the corresponding sample of privatelabel loans, but the magnitudes are still relatively small (10 to 20 percent difference from the unconditional mean). Finally, in Panel C, we see strong evidence for both the logit and Cox specifications, that delinquent private-label loans prepayed more often than portfolio loans. The differences are statistically significant for every one of the subsamples.

\subsection{Redefault Probabilities and Cure Rates}

In the previous subsections, we showed that there is little difference in the frequency of mortgage loan modifications between servicers of loans held in a private trust versus loans held in portfolio. There are two potential reasons that may explain the failure of those exercises to pick up important differences in servicer behavior that may truly exist. First, it may be that contract frictions in securitization trusts do not result in substantial differences in the frequency of modifications (the extensive margin) but do result in significant differences in the intensive margin, with respect to the types of modifications performed, the extent to which contract terms are modified, and, more broadly, the care or effort expended in each modification by private-label servicers compared to that expended by portfolio servicers. Second, there may be a type of renegotiation that our algorithm does not identify, but that is used to a large extent in loss mitigation efforts and used differently by servicers of privatelabel loans than by servicers of portfolio loans. For example, forms of forbearance, which are often called repayment plans in the industry, would not be picked up by our algorithm. ${ }^{25}$ In this subsection, we use the LPS data to attempt to address these possibilities.

We perform two separate empirical exercises to address each of these concerns in turn. First, we compare redefault rates of private-label modified loans with those of portfolio modified loans. We define redefault as a loan that is 60 days delinquent or more, in foreclosure process or already foreclosed and now owned by the lender (REO for "real-estate-owned") six months after the time of the modification. If there are important differences in the manner by which servicers of private-label loans modify mortgages relative to the foreclosure procedures of servicers of portfolio loans, then we would expect to see significant differences in the subsequent performance of modified loans.

Second, to address the possibility that our algorithm misses an important aspect of

\footnotetext{
${ }^{25}$ However, as we argued above, PSAs do not contain restrictions on repayment plans, because they do not involve changing the terms of the mortgage. Thus, we would argue that differences in forbearance behavior that might exist could not be the result of contract frictions in securitization trusts.
} 
renegotiation, we compare the cure rates of seriously delinquent, private-label loans to those of seriously delinquent portfolio loans. The idea behind this exercise is that any appreciable difference in servicer renegotiation behavior will manifest itself in differences in cure rates. It is important to stress however, that differences in servicer renegotiation behavior are only one potential explanation for differences that may exist in cure rates. To put this idea in the terms of logical reasoning, differences in cure rates are a necessary condition for significant differences in renegotiation behavior, but they are not a sufficient condition.

Table 8 contains the results of the redefault analysis. The first observation to note from the table is that the unconditional probability that a modified mortgage redefaults in this six-month period is very large, at about 20-40 percent for payment-reducing modifications (Panel A), and 40-50 percent for all modifications (Panel B). We argue below that the high level of redefault rates could explain why we observe so few modifications — very often they do not lead to successful outcomes even as little as six months after the modification. The second observation to note is that there is no statistically significant difference between the redefault rates of private-label loans and those of portfolio loans, once the observable characteristics of the mortgages are taken into account (this is valid for all of the subsamples). These results, combined with the statistics displayed in Table 4 suggest that there are no substantial differences in either the type of modification employed or in the care/effort expended by the two types of servicers.

Table 9 shows the results of logit models for the probability that a seriously delinquent loan subsequently cures. Our definition of a cure is that the loan is either current, 30-days delinquent, or prepaid after 12 months following the first 60-day delinquency. The first important point to make is that the unconditional cure probabilities are large (around 30 percent). Given that the unconditional modification probability is about 8 percent, this means that many loans cure without any intervention on the part of servicers. The second important observation to note in this table is that the cure probabilities for portfolio loans and private-label loans are quite similar. The unconditional cure probability is smaller by about 4.4 percentage points for private-label loans in the whole sample, but that is reduced to only 2.2 percentage points (statistically significant) when we control for observable characteristics of the loans and borrowers. We also include results for the subsamples of interest in columns $2-5$. For each of the subsamples the sign of the difference actually reverses, as private-label loans were more likely to cure (the marginal effects are statistically significant, with the exception of the FICO $<620$ sample). This is an important robustness check, as we argued above that unobserved heterogeneity is likely to be less of a problem in the subsamples (especially for the non-missing documentation status and DTI ratios sample and the full documentation sample). Thus, the change in the sign of the differences in 
cure rates between private-label servicers and portfolio servicers suggests that unobserved heterogeneity between the two loan types plays an important role.

\section{Understanding the Empirical Results}

If securitization does not block renegotiation, then why is it so rare? In this section, we build a simple model of the renegotiation decision, which, in a stylized way, mirrors the net present value (NPV) calculation that servicers are supposed to perform when deciding whether to offer a borrower a modification. We show that servicer uncertainty about whether the borrower will redefault even after successful renegotiation or uncertainty about whether the borrower will cure without renegotiation can dramatically affect the NPV calculation, ruining what a naive observer might think of as a "win-win" deal for the borrower and lender. While many proponents of modification are aware of the former problem, "redefault risk," none seem to be aware of the latter problem, which we call "self-cure risk."

In addition to the model, we also provide institutional evidence in this section that supports our arguments and findings above. This includes evidence of low modification frequencies in previous housing busts, well before the advent of securitization trusts; the equal treatment provision statements contained in the PSAs, which direct the servicer to behave as if it was in fact the investor of the mortgage-backed security and thus the owner of the mortgages; and finally, the absence of lawsuits to date directed at servicers by investors in mortgage-backed securities, which one would expect to find if modifications were unambiguously better than foreclosures from an NPV calculation.

\subsection{A Simple Model of Loss Mitigation}

We consider a simple model of a lender's decision to modify a delinquent loan. ${ }^{26}$ There are three periods: $t=0,1,2$. The borrower owes a mortgage payment of size $m$ at time 1 and is due to repay the loan balance $M$ in period 2. The mortgage is collateralized by a house, which is worth $P_{1}$ and $P_{2}$ in periods 1 and 2 , respectively. In period 0 , the lender has to make a decision to either modify the loan, or do nothing. If the lender fails to modify the loan, then, with probability $\alpha_{0}$, the borrower will default in period 1 , and the lender will foreclose and recover $P_{1}-\lambda$, where $\lambda$ is the cost of foreclosing on the property. If the borrower does not default next period, then the lender receives the periodic payment $m$ in period 1, and the borrower repays the loan in full in period 2. The value to the lender of

\footnotetext{
${ }^{26}$ Our model shares some basic similarities with the approach in Ambrose and Capone (1996), who also identify a role for self-cure risk in assessing the profitability of a loss mitigation action.
} 
the loan without modification equals the present discounted value of the cash flow:

$$
\alpha_{0} * \min \left[\left(P_{1}-\lambda\right), M\right]+\left(1-\alpha_{0}\right)[m+(1 / R) M]
$$

where we ignore discounting for the first period because there is no income in period 0 . If the lender modifies the loan, then we assume that the borrower makes a reduced periodic payment $m^{*}$ in period 1 with certainty, but then either defaults with probability $\alpha_{1}$ or repays a modified amount $M^{*}$ in period 2 . The value to the lender of the modified loan is:

$$
m^{*}+(1 / R) \alpha_{1} * \min \left[\left(P_{2}-\lambda\right), M^{*}\right]+\left(1-\alpha_{1}\right)(1 / R) M^{*}
$$

Taking the difference between expressions (2) and (1) yields the following proposition:

Proposition 1 Modification makes sense if:

$$
\begin{aligned}
\left(\alpha_{0}-\alpha_{1}\right)\left[m^{*}+\frac{1}{R} M^{*}-\min \right. & {\left.\left[\left(P_{1}-\lambda\right), M\right]\right] } \\
- & \left(1-\alpha_{0}\right)\left[m+\frac{1}{R} M-\left(m^{*}+\frac{1}{R} M^{*}\right)\right] \\
& +\alpha_{1}\left[m^{*}+\frac{1}{R} \min \left[\left(P_{2}-\lambda\right), M^{*}\right]-\min \left[\left(P_{1}-\lambda\right), M\right]\right]>0 .
\end{aligned}
$$

To interpret equation (3), divide the population of borrowers into three groups. The first group, with mass of $\alpha_{0}-\alpha_{1}$ are borrowers who will repay in full with a modification but who will default otherwise. For this group, the investor gains the difference between the present value of the modified repayment $m^{*}+\frac{1}{R} M^{*}$ and the recovery given foreclosure, $\min \left[\left(P_{1}-\lambda\right), M\right]$. The second group, with mass $1-\alpha_{0}$, includes borrowers who will repay whether or not they receive a modification. For this group, the investor loses the difference between full repayment and the modified repayment. Gerardi and Willen (2009) refer to the first two terms as Type I error and Type II error, respectively, in analogy with the statistical concepts. In this context, Type I error corresponds to the cost of not renegotiating loans that need modifying, while Type II error corresponds to the cost of modifying loans that would be repaid in the absence of assistance. The third term, with mass $\alpha_{1}$, includes borrowers who will default regardless of whether they receive a modification. For these borrowers, modification yields a periodic payment, but postpones foreclosure. Whether this is good or bad for the lender depends on the evolution of house prices and the rate at which the lender discounts the cash flow.

To illustrate the implications of the model, we compute some simple comparative statics. All else being equal, an increase in $\alpha_{0}$ makes modification more attractive to the investor, while an increase in $\alpha_{1}$ makes modification less attractive. Intuitively, a higher $\alpha_{0}$ means 
higher Type I error and lower Type II error, and a higher $\alpha_{1}$ implies higher Type II error. Since, in general, one would think that $\alpha_{0}$ and $\alpha_{1}$ would move in the same direction across borrowers, it is useful to note that an increase the gap, $\alpha_{0}-\alpha_{1}$, makes modification more attractive.

We make three points about the model. First, when looking at the data, it is not sufficient to show that one would recover more from a modified loan than from foreclosure ex post, to prove that modification is ex ante optimal. To prove that a modification makes sense from the perspective of the lender, one must show that the Type I error, the value of the modified loans that would have defaulted, exceeds the Type II error, the value of the modified loans that would have paid off in the absence of modification. White (2009), among many others, focuses entirely on Type I error:

The average loss for the 21,000 first mortgages liquidated in November was $\$ 145,000$, representing an average loss of 55 percent of the amount due. Losses on second lien mortgages were close to 100 percent. In comparison, for the modified loans with some amount of principal or interest written off, the average loss recognized was $\$ 23,610$. This seven-to-one difference between foreclosure losses and modification write-offs is striking, and lies at the heart of the failure of the voluntary mortgage modification program. At a minimum, there is room for servicers to be more generous in writing down debt for the loans they are modifying, while still recovering far more than from foreclosures in the depressed real estate market of late 2008. I will consider some of the reasons for this apparently irrational behavior in a later section. ${ }^{27}$

To see why this is wrong, take an extreme example with $\alpha_{1}=0$. In that case, the gain to modifications equals

$$
\alpha_{0}\left[m^{*}+\frac{1}{R} M^{*}-\min \left[\left(P_{1}-\lambda\right), M\right]\right]-\left(1-\alpha_{0}\right)\left[m+\frac{1}{R} M-\left(m^{*}+\frac{1}{R} M^{*}\right)\right]
$$

With $\alpha_{0}$ sufficiently low, modification will not make sense. To be clear, our criticism of White (2009) and others has nothing to do with the possibility that the modified loan will default, as we have assumed here that the modified loan will pay off in full.

The second point here is that both the rate at which lenders discount future payoffs and the evolution of prices affect the gains to modification. For mass $\left(1-\alpha_{1}\right)$ of the borrowers, modification will simply delay foreclosure. In that case, the lender will get some extra income from any mortgage payments the borrower makes before redefaulting, but the lender has to wait longer to obtain the final payout and will get less if prices continue to fall.

\footnotetext{
${ }^{27}$ White (2009), p. $14-15$
} 
The third point is that the lender's information set plays a crucial role here, and one could argue that it should only contain information outside the control of the borrower. This would limit the set to the origination characteristics of the loan, prices, and interest rates. Employment status, income, and marital status all present problems, although they can be partially overcome - as in the case of unemployment insurance. Delinquency status, which seems a natural candidate, is a difficult issue. On one hand, a borrower has virtually complete control over it. On the other hand, it is a costly signal, as a 60-day delinquency does adversely affect one's credit history and future access to credit markets. Thus, when considering ways to design a profitable modification program, which implies attempting to maximize $\alpha_{0}$ and minimize $\alpha_{1}$, a lender must restrict its information set to a relatively small set of variables that are contemporaneously exogenous to the borrower.

\subsection{Institutional Evidence}

While the results from Section 3 may be surprising to market commentators who believe that contract frictions inherent in securitization trusts are preventing large-scale modification efforts in mortgage markets, we argue in this section that both historical evidence and evidence from securitization contracts actually support our findings.

First, we look at history. If securitization, or more precisely private-label securitization, inhibits renegotiation, then we would expect that renegotiation would have been common in the 1990s, when there was little private-label securitization, or in the 1970s, when securitization itself was rare. But, the historical evidence we have does not bear that out. In 1975, Touche Ross surveyed loss mitigation activities at savings and loans and found, "Lenders... were unwilling to either modify loans through extended terms or refinancing to a lower rate." ${ }^{28}$ In the 1990s, a report commissioned by Congress to study foreclosure alternatives, said, "Along with loan modifications, long-term forbearance/repayment plans are the most under utilized foreclosure avoidance tools currently available to the industry." ${ }^{29}$

Second, many observers have focused on institutional factors that inhibit loan modification when the loan is securitized, but other factors may play a similar role for portfolio lenders as well. In particular, accounting rules force lenders to take writedowns at the time of the modification (reducing Tier II capital), to identify modified loans as troubled debt restructurings (under FAS 15), and also to impose burdensome reporting requirements on modified loans including loan-specific allowances for potential losses (under FAS 114). Additionally, payments made by borrowers for loans that are subject to "troubled debt re-

\footnotetext{
${ }^{28}$ Capone (1996), p. 20-21.

${ }^{29}$ Capone (1996), p. x.
} 
structurings" are recognized only as principal repayments and generate to interest income until the bank can demonstrate that a borrower is "performing." All of the above accounting requirements potentially make modifications costly for a bank. Downey Financial, for example, attempted to refinance current borrowers out of risky option ARMs into safer, fixed-rate instruments and argued that the change should not affect their balance sheet because the borrowers had never missed payments. However, their accountants viewed the refinancings as "troubled debt restructurings," and forced the firm to restate the share of nonperforming assets for November 2007 to 5.77 percent from 3.65 percent. $^{30}$

If modifications were truly in the best financial interest of investors in mortgage-backedsecurities (MBS) as many commentators have alleged, we would expect to see concern on their part regarding the low levels of modifications performed to date. But, according to Cordell, Dynan, Lehnert, Liang, and Mauskopf (2008b), who interviewed a number of MBS investors, they (the investors) are not concerned that servicers are foreclosing on many more mortgages than they are modifying. Thus, there does not seem to be much concern by market participants that either incentives or contract frictions are inhibiting servicers from performing loan modifications. The evidence in the literature seems to suggest a small role for contract frictions in the context of renegotiation. In a 2007 study of a small sample of PSAs, Credit Suisse found that fewer than 10 percent of the contracts ruled out modifications completely, while approximately 40 percent allowed modifications, but with quantity restrictions, ${ }^{31}$ and the rest, about half, contained no restrictions on renegotiation behavior. Hunt (2009) also analyzed a sample of subprime PSAs and concluded that outright modification bans were extremely rare. A 2008 report by the COP analyzed a number of securitized mortgage pools with quantity restrictions and concluded that none of the restrictions were binding. In terms of incentive issues, Hunt (2009) found that most of the contracts in his sample explicitly instructed the mortgage servicer to behave as if it were the owner of the pool of the loans:

The most common rules [in making modifications] are that the servicer must follow generally applicable servicing standards, service the loans in the interest of the certificate holders and/or the trust, and service the loans as it would service loans held for its own portfolio. Notably, these conditions taken together can be read as attempting to cause the loans to be serviced as if they had not been securitized. (p. 8, insertion added)

\footnotetext{
${ }^{30}$ http://www.housingwire.com/2008/01/14/downey-financial-accounting-rules-suck/

${ }^{31}$ The quantity restrictions often took the form of a limit (usually 5 percent) on the percentage of mortgages in the pool that could be modified without requesting permission from the trustee.
} 


\section{Conclusion}

There is widespread concern that an inefficiently low number of mortgages have been modified during the current crisis, and that this has led to excessive foreclosure levels, leaving both families and investors worse off. We use a large dataset that accounts for approximately 60 percent of mortgages in the United States originated between 2005 and 2007, to shed more light on the determinants of mortgage modification, with a special focus on the claim that delinquent loans have different probabilities of renegotiation depending on whether they are securitized by private institutions or held in a servicer's portfolio. By comparing the relative frequency of renegotiation between private-label and portfolio mortgages, we are able to shed light on the question of whether institutional frictions in the secondary mortgage market are inhibiting the modification process from taking place.

Our first finding is that renegotiation in mortgage markets during this period was indeed rare. In our full sample of data, approximately 3 percent of the seriously delinquent borrowers received a concessionary modification in the year following their first serious delinquency, while fewer than 8 percent received any type of modification. These numbers are extremely low, considering that foreclosure proceedings were initiated on approximately half of the loans in the sample and completed for almost 30 percent of the sample. Our second finding is that a comparison of renegotiation rates for private-label loans and portfolio loans, while controlling for observable characteristics of loans and borrowers, yields economically small, and for the most part, statistically insignificant differences. This finding holds for a battery of robustness tests we consider, including various definitions of modification, numerous subsamples of the data, including subsamples for which we believe unobserved heterogeneity to be less of an issue, and consideration of potential differences along the intensive margin of renegotiation.

Since we conclude that contract frictions in securitization trusts are not a significant problem, we attempt to reconcile the conventional wisdom held by market commentators, that modifications are a win-win proposition from the standpoint of both borrowers and lenders, with the extraordinarily low levels of renegotiation that we find in the data. We argue that the data are not inconsistent with a situation in which, on average, lenders expect to recover more from foreclosure than from a modified loan. At face value, this assertion may seem implausible, since there are many estimates that suggest the average loss given foreclosure is much greater than the loss in value of a modified loan. However, we point out that renegotiation exposes lenders to two types of risks that are often overlooked by market observers and that can dramatically increase its cost. The first is "self-cure risk," which refers to the situation in which a lender renegotiates with a delinquent borrower who 
does not need assistance. This group of borrowers is non-trivial according to our data, as we find that approximately 30 percent of seriously delinquent borrowers "cure" in our data without receiving a modification. The second cost comes from borrowers who default again after receiving a loan modification. We refer to this group as "redefaulters," and our results show that a large fraction (between 30 and 45 percent) of borrowers who receive modifications, end up back in serious delinquency within six months. For this group, the lender has simply postponed foreclosure, and, if the housing market continues to decline, the lender will recover even less in foreclosure in the future.

We believe that our analysis has some important implications for policy. First, "safe harbor provisions," which are designed to shelter servicers from investor lawsuits, are unlikely to have a material impact on the number of modifications and thus will not significantly decrease foreclosures. Second, and more generally, if the presence of self-cure risk and redefault risk do make renegotiation less appealing to investors, the number of easily "preventable" foreclosures may be far smaller than many commentators believe. 


\section{A Appendix: Identifying Modifications in the LPS Dataset}

In this section we discuss in detail the assumptions that we used to identify modified loans in the LPS dataset. The LPS dataset is updated on a monthly basis, and the updated data include both new mortgages originated and a snapshot of the current terms and delinquency status of outstanding mortgages. Essentially, for a given mortgage, we compare the updated terms to the terms at origination, as well as the change in terms from the proceeding month, and if there is a material change over and above the changes stipulated in the mortgage contract, then we assume that the contract terms of the mortgage have been modified.

\section{A.1 Interest Rate Reductions}

We use a different set of rules to identify reduced interest rates for fixed-rate mortgages (FRM) and adjustable-rate mortgages (ARM). In principle, identifying a rate change for an FRM should be easy, since by definition the rate is fixed for the term of the mortgage. However, after a detailed inspection of the LPS data, it became apparent that some of the smaller rate fluctuations were likely due to measurement error rather than to an explicit modification. Thus, we adopt a slightly more complex criterion: The difference between the rate at origination and the current rate must be greater than 50 basis points; and the difference between the rate in the previous month and the current rate must be greater than 50 basis points; and either the mortgage must be 30-days delinquent with the loan currently in loss mitigation proceedings (as reported by the servicer) or the difference between the rate in the previous month and the current rate must be greater than 300 basis points (which allows for the possibility that a loan that is current could feasibly qualify for a modification).

Identifying interest rate reductions for ARMs is slightly more complicated, since by definition the interest rate is variable and can move both up and down. The LPS data contain the information necessary to figure out how much the interest rate should move from month to month. This rate is often referred to as the fully indexed rate, as it is normally specified as a fixed spread above a common nominal interest rate. The LPS dataset contains information regarding the initial rate, the appropriate index rate, and the spread between the index and the mortgage rate. In addition, the majority of ARMs are characterized by a period at the beginning of the contract in which the interest rate is held constant (these mortgages are often referred to as hybrid ARMs). At the end of this period, the interest rate adjusts (or resets) to a certain spread above an index rate and then subsequently adjusts at a specific frequency. The LPS dataset also contains information regarding the length of 
the initial fixed period, enabling us to identify this period in the data and determine the point at which the interest rate should begin to adjust (we refer to this period as the reset date). Our criterion for identifying an interest rate reduction for an ARM is as follows: The difference between the rate at origination and the current rate must be greater than 50 basis points; and the difference between the rate in the previous month and the current rate must be greater than 50 basis points; and if the reset date has passed, then the difference between the fully-indexed rate and the current rate must be at least 100 basis points ; and either the mortgage must be 30-days delinquent with the loan currently in loss mitigation proceedings (as reported by the servicer) or the difference between the rate in the previous month and the current rate must be greater than 300 basis points (which allows for the possibility that a loan that is current could feasibly qualify for a modification). In addition, we allow for more modest month-to-month decreases in the interest rate (200 to 300 basis points) as long as there is also a positive change in the delinquency status of the loan (that is, the loan is reported to be less delinquent). Our inspection of the data suggests that the majority of modifications involve a resetting of the delinquency status back to current, or a minor delinquency, so conditioning on this change likely eliminates many false positives.

\section{A.2 Term Extensions}

In theory, it should be straightforward to identify term extensions in the LPS data, but it can be tricky to do so because of possible measurement error in the variable that measures the remaining maturity of each loan. We defined a term extension in the LPS dataset to be a case in which the loan was at least 30-days delinquent at some point and the number of years remaining increases by at least 20 months or the change in number of years remaining is greater than the difference between the original term of the loan and the remaining term (for example, if the original maturity is 360 months, and the loan has 350 months remaining, then the increase in length must be at least 10 months) and, finally, either the monthly payment decreases or the principal balance increases or the loan is in loss mitigation.

\section{A.3 Principal Balance Reductions}

A reduction in the remaining balance of a mortgage is perhaps the most difficult type of modification to identify because of the prevalence of "curtailment" or partial prepayment among mortgage borrowers. For example, it is common for borrowers to submit extra mortgage payments in order to pay down the loan at a faster rate. For this reason, we were forced to adopt strict criteria to limit the number of false positives. Our criterion for identifying a principal balance reduction is as follows: The month-to-month decrease in 
the remaining principal balance must be at least -10 percent and cannot be more than -30 percent (the upper bound does not matter as much as the lower bound - we experimented with -40 percent and -50 percent, but did not find a substantial difference); the principal balance recorded in the previous month must be greater than $\$ 25,000$ (since we throw second liens out, and look only at mortgages originated after 2004, this cutoff does not bind often); the month-to-month payment change must be negative (there are only a few cases in which the principal balance is reduced without a corresponding decrease in the payment, but in these cases the term is extended, and thus is picked up in our code for identifying term extensions); and, finally, the mortgage must be either 30-days delinquent or currently in loss mitigation proceedings (as reported by the servicer).

\section{A.4 Principal Balance Increases}

For interest-only and fully-amortizing mortgages, identifying an increase in the principal balance due to the addition of arrears is relatively straightforward. It becomes trickier for mortgages that allow for negative amortization, as the principal balance is allowed to increase over the course of the contract, by definition. For interest-only and fully-amortizing mortgages our criterion is: The month-to-month principal balance must increase by at least 0.5 percent (to rule out measurement error in the data); the loan must have been at least 30-days delinquent at the time of the balance increase; and, finally, the month-to-month payment change must be positive unless there is also a corresponding increase in the term of the loan. For mortgages that allow for negative amortization, the criterion is similar, except that the balance increase must be at least 1 percent and there must be a positive change in the delinquency status of the loan. 


\section{References}

Ambrose, B., R. Buttimer Jr, and C. Capone (1997). Pricing Mortgage Default and Foreclosure Delay. Journal of Money, Credit É Banking $29(3)$.

Ambrose, B. and C. Capone (1996). Cost-benefit analysis of single-family foreclosure alternatives. The Journal of Real Estate Finance and Economics 13(2), 105-120.

Ambrose, B. and C. Capone (1998). Modeling the conditional probability of foreclosure in the context of single-family mortgage default resolutions. Real Estate Economics 26(3), 391-429.

Ambrose, B. and C. Capone (2000). The hazard rates of first and second defaults. The Journal of Real Estate Finance and Economics 20(3), 275-293.

Asquith, P., R. Gertner, and D. Scharfstein (1994). Anatomy of financial distress: An examination of junk-bond issuers. Quarterly Journal of Economics 109(3), 625-658.

Bolton, P. and D. S. Scharfstein (1996). Optimal debt structure and the number of creditors. Journal of Political Economy 104(1), 1-25.

Capone, C. A. (1996). Providing Alternatives to Mortgage Foreclosure: A Report to Congress. US Department of Housing and Urban Development.

Congressional Oversight Panel (2009). Foreclosure Crisis: Working Toward a Solution. March Oversight Report.

Cordell, L., K. Dynan, A. Lehnert, N. Liang, and E. Mauskopf (2008a). The incentives of mortgage servicers: Myths and realities. Federal Reserve Board Finance and Economics Discussion Series 2008-46.

Cordell, L., K. Dynan, A. Lehnert, N. Liang, and E. Mauskopf (2008b). The Incentives of Mortgage Servicers: Myths and Realities. Finance and Economics Discussion Series, Federal Reserve Board 46 .

Cutts, A. and R. Green (2005). Innovative servicing technology: smart enough to keep people in their houses? Building Assets, Building Credit: Creating Wealth In LowIncome Communities, 348-377.

Cutts, A. and W. Merrill (2008). Interventions in Mortgage Default: Policies and Practices to Prevent Home Loss and Lower Costs. Technical report, Working Paper.

Danis, M. A. and A. N. Pennington-Cross (2005). The Delinquency of Subprime Mortgages. SSRN eLibrary. 
Eggert, K. (2007). Comment on michael a. stegman et al.: What prevents loan modifications? Housing Policy Debate 18(2).

Foote, C., K. Gerardi, L. Goette, and P. Willen (2009, June). Reducing foreclosures: No easy answers. Working Paper 15063, National Bureau of Economic Research.

Foote, C., K. Gerardi, and P. Willen (2008). Negative equity and foreclosure: Theory and evidence. Journal of Urban Economics 6(2), 234-245.

Gan, Y. H. and C. Mayer (2006). Agency conflicts, asset substitution, and securitization. NBER Working Paper No. 12359.

Geanakoplos, J. and S. Koniak (2008). The best way to help homeowners - and the economy. Available at http://cowles.econ.yale.edu/ gean/crisis/index.htm.

Gelpern, A. and A. Levitin (2009). Rewriting frankenstein contracts: Workout prohibitions in mortgage-backed securities. http://ssrn.com/abstract $=1323546$.

Gerardi, K. and P. Willen (2009). Suprime Mortgages, Urban Neighborhoods and Foreclosure. The B.E. Journal of Economic Analysis 8 Policy 9 (3 (Symposium).

Hunt, J. P. (2009). What do subprime securitization contracts actually say about loan modification? Berkeley Center for Law, Business and the Economy working paper.

Lauria, M., V. Baxter, and B. Bordelon (2004). An investigation of the time between mortgage default and foreclosure. Housing Studies 19(4), 581-600.

Levitin, A. (2009a). Helping homeowners: Modification of mortgages in bankruptcy. Harvard Law \& Policy Review Online 3.

Levitin, A. (2009b). Resolving the foreclosure crisis: Modification of mortgages in bankruptcy. Wisconsin Law Review.

Mason, J. (2007). Mortgage Loan Modification: Promises and Pitfalls.

Mulherin, J. and W. Muller (1987). Volatile interest rates and the divergence of incentives in mortgage contracts. Journal of Law, Economics, and Organization 3(1), 99-115.

Pennington-Cross, A. (2009). The duration of foreclosures in the subprime mortgage market: a competing risks model with mixing. The Journal of Real Estate Finance and Economics, 1-21.

Pennington-Cross, A. and G. Ho (2006). Loan Servicer Heterogeneity and the Termination of Subprime Mortgages. 
Piskorski, T., A. Seru, and V. Vig (2009). Securitization and distressed loan renegotiation: Evidence from the subprime mortgage crisis. Chicago Booth School of Business Research Paper No. 09-02.

Quercia, R., L. Ding, and J. Ratcliffe (2009). Loan Modifications and Redefault Risk.

Riddiough, T. and S. Wyatt (1994a). Strategic default, workout, and commercial mortgage valuation. The Journal of Real Estate Finance and Economics 9(1), 5-22.

Riddiough, T. and S. Wyatt (1994b). Wimp or tough guy: Sequential default risk and signaling with mortgages. The Journal of Real Estate Finance and Economics 9(3), 299-321.

Springer, T. and N. Waller (1993). Lender forbearance: evidence from mortgage delinquency patterns. Real Estate Economics 21(1), 27-46.

Stegman, M., R. Quercia, J. Ratcliffe, L. Ding, W. Davis, W. Li, K. Ernst, A. Aurand, and S. Van Zandt (2007). Preventive Servicing Is Good for Business and Affordable Homeownership Policy. Housing Policy Debate 18(2).

White, A. M. (2008). Rewriting Contracts, Wholesale: Data on Voluntary Mortgage Modifications from 2007 and 2008 Remittance Reports. Fordham Urban Law Journal forthcoming.

White, A. M. (2009). Deleveraging the American Homeowner: The Failure of 2008 Voluntary Mortgage Contract Modifications. Connecticut Law Review forthcoming.

Zingales, L. (2008). Plan b. Economists' Voice 5(6), 4. 
Table 1: Examples of modifications in the data.

Example 1: Servicer cuts interest rate, capitalizes arrears in the balance of the loan and extends term to 40 years.

\begin{tabular}{rccccc}
\hline \hline & MBA & Interest & Monthly & Outstanding & $\begin{array}{c}\text { Remaining } \\
\text { Date }\end{array}$ \\
Delinq. Stat. & Rate & Payment & Balance & Term in Months \\
\hline $2008 \mathrm{~m} 10$ & 9 & 6.5 & 907 & 141,323 & 340 \\
$2008 \mathrm{~m} 11$ & 9 & 6.5 & 907 & 141,323 & 339 \\
$2008 \mathrm{~m} 12$ & 9 & 6.5 & 907 & 141,323 & 338 \\
$2009 \mathrm{~m} 1$ & $\mathrm{C}$ & 4.5 & 660 & 146,686 & 479 \\
\hline \hline
\end{tabular}

Example 2: Servicer capitalizes arrears into the balance of the loan but otherwise leaves the loan unchanged.

\begin{tabular}{rccccc}
\hline \hline Date & $\begin{array}{c}\text { MBA } \\
\text { Delinq. Stat. }\end{array}$ & $\begin{array}{c}\text { Interest } \\
\text { Rate }\end{array}$ & $\begin{array}{c}\text { Monthly } \\
\text { Payment }\end{array}$ & $\begin{array}{c}\text { Outstanding } \\
\text { Balance }\end{array}$ & $\begin{array}{c}\text { Remaining } \\
\text { Term in Months }\end{array}$ \\
\hline $2008 \mathrm{~m} 5$ & 6 & 9.25 & 1,726 & 208,192 & 346 \\
$2008 \mathrm{~m} 6$ & 9 & 9.25 & 1,726 & 208,192 & 346 \\
$2008 \mathrm{~m} 7$ & 9 & 9.25 & 1,726 & 208,192 & 346 \\
$2008 \mathrm{~m} 8$ & $\mathrm{C}$ & 9.25 & 1,815 & 218,316 & 341 \\
$2008 \mathrm{~m} 9$ & $\mathrm{C}$ & 9.25 & 1,815 & 218,184 & 340 \\
\hline \hline
\end{tabular}


Table 2: Robustness of the modifications algorithm

False positives by type of modifications

\begin{tabular}{lrr}
\hline \hline & \# of Modifications & False \\
& Using WF CTS Data & Positives \\
\hline FRM Rate Reduction & 5,381 & $8.0 \%$ \\
ARM Rate Reduction & 8,951 & $22.0 \%$ \\
Principal Reductions & 470 & $1.9 \%$ \\
Principal Increases & 13,010 & $12.8 \%$ \\
Term Increases & 394 & $2.3 \%$ \\
\hline \hline
\end{tabular}

\section{Overall success of algorithm}

\begin{tabular}{lrrr}
\hline \hline & No Mod Using & Mod Using & \\
& Our Algorithm & Our Algorithm & Total \\
\hline No Mod in WF Data & $2,329,187$ & 3,559 & $2,332,746$ \\
Mod in WF Data & 3,627 & 17,514 & 21,141 \\
\hline Total & $2,332,814$ & 21,073 & $2,353,887$ \\
\hline \hline
\end{tabular}

Notes: We test our algorithm on a dataset of securitized mortgages in which the trustee has identified modifications (data is from Wells Fargo Trustee Services). The lower panel shows that about $17.2 \%$ of our modifications are false positives, meaning that we identify modifications but the trustee does not and about $16.9 \%$ are false negatives, meaning that the trustee identifies a modification but we do not. 
Table 3: Modification Statistics

\section{(1) By Type of Modification: 2007:Q1-2008:Q4}

\begin{tabular}{|c|c|c|c|c|c|c|c|c|c|}
\hline & $\begin{array}{l}\text { \# Loans } \\
\text { Modified }\end{array}$ & \multicolumn{2}{|c|}{$\begin{array}{l}\text { Interest Rate } \\
\text { Reductions }\end{array}$} & \multicolumn{2}{|c|}{$\begin{array}{l}\text { Principal Balance } \\
\text { Reductions }\end{array}$} & \multicolumn{2}{|c|}{$\begin{array}{l}\text { Principal Balance } \\
\text { Increases }\end{array}$} & \multicolumn{2}{|c|}{ Term Extensions } \\
\hline & & \# & $(\%$ total $)$ & $\#$ & (\% total $)$ & $\#$ & (\% total) & $\#$ & (\% total) \\
\hline 2007:Q1 & 10,940 & 600 & 5.3 & 700 & 6.2 & 8,660 & 76.4 & 1,380 & 12.2 \\
\hline 2007:Q2 & 14,600 & 820 & 5.4 & 550 & 3.7 & 11,630 & 77.3 & 2,050 & 13.6 \\
\hline 2007:Q3 & 17,720 & 770 & 4.1 & 810 & 4.3 & 15,170 & 81.2 & 1,940 & 10.4 \\
\hline 2007:Q4 & 27,150 & 2,990 & 9.7 & 700 & 2.3 & 22,520 & 72.8 & 4,740 & 15.3 \\
\hline 2008:Q1 & 36,230 & 6,010 & 13.8 & 900 & 2.1 & 32,100 & 73.8 & 4,500 & 10.3 \\
\hline 2008:Q2 & 44,750 & 9,050 & 16.4 & 1,300 & 2.4 & 39,750 & 72.1 & 5,030 & 9.1 \\
\hline 2008:Q3 & 62,190 & 16,280 & 20.3 & 940 & 1.2 & 56,940 & 70.9 & 6,110 & 7.6 \\
\hline 2008:Q4 & 74,800 & 28,630 & 26.7 & 1,450 & 1.4 & 65,960 & 61.5 & 11,230 & 10.5 \\
\hline
\end{tabular}

\section{(2) By Payment Change}

\begin{tabular}{|c|c|c|c|c|c|c|c|c|c|c|}
\hline & \multicolumn{5}{|c|}{ Payment Decreases } & \multicolumn{5}{|c|}{ 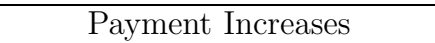 } \\
\hline & \multirow[t]{2}{*}{$\#$} & \multicolumn{2}{|c|}{ mean $\Delta$} & \multicolumn{2}{|c|}{ median $\Delta$} & \multirow[t]{2}{*}{$\#$} & \multicolumn{2}{|c|}{ mean $\Delta$} & \multicolumn{2}{|c|}{ median $\Delta$} \\
\hline & & $\$$ & $\%$ & $\$$ & $\%$ & & $\$$ & $\%$ & $\$$ & $\%$ \\
\hline 2007:Q1 & 2,080 & -492 & -13.2 & -157 & -10.0 & 5,020 & 106 & 6.7 & 62 & 4.4 \\
\hline 2007:Q2 & 2,060 & -464 & -12.7 & -141 & -9.6 & 7,710 & 120 & 7.0 & 63 & 4.4 \\
\hline 2007:Q3 & 2,470 & -290 & -12.9 & -125 & -9.7 & 10,380 & 110 & 6.7 & 60 & 4.3 \\
\hline 2007:Q4 & 5,600 & -367 & -15.3 & -159 & -11.7 & 14,540 & 100 & 5.9 & 59 & 3.9 \\
\hline 2008:Q1 & 11,500 & -358 & -14.0 & -210 & -13.2 & 18,720 & 108 & 6.5 & 62 & 4.3 \\
\hline 2008:Q2 & 18,660 & -425 & -16.1 & -239 & -14.1 & 20,770 & 124 & 7.4 & 69 & 4.1 \\
\hline 2008:Q3 & 31,770 & -562 & -21.5 & -365 & -20.2 & 26,400 & 124 & 6.3 & 63 & 3.6 \\
\hline 2008:Q4 & 48,000 & -503 & -22.9 & -315 & -21.7 & 22,520 & 104 & 6.0 & 53 & 3.6 \\
\hline
\end{tabular}

\section{(3) Loan Characteristics of Modified Mortgages}

\begin{tabular}{|c|c|c|c|c|c|c|c|c|c|c|}
\hline & \multicolumn{5}{|c|}{$\overline{\text { All Loans }}$} & \multicolumn{5}{|c|}{ Modifications } \\
\hline & \# & mean & $\mathrm{p} 25$ & $\mathrm{p} 50$ & $\mathrm{p} 75$ & \# & mean & p25 & $\mathrm{p} 50$ & p75 \\
\hline FICO (at origination) & $1,892,777$ & 706 & 660 & 713 & 762 & 17,533 & 622 & 580 & 621 & 662 \\
\hline LTV (at origination) & $2,250,162$ & 75 & 67 & 79 & 85 & 21,675 & 82 & 78 & 80 & 90 \\
\hline DTI (at origination) & $1,346,093$ & 37 & 28 & 38 & 45 & 13,945 & 41 & 35 & 41 & 47 \\
\hline Mortgage balance (at origination) & $2,267,497$ & $231 \mathrm{~K}$ & $121 \mathrm{~K}$ & $185 \mathrm{~K}$ & $288 \mathrm{~K}$ & $21 \mathrm{~K}$ & $234 \mathrm{~K}$ & $121 \mathrm{~K}$ & $186 \mathrm{~K}$ & $294 \mathrm{~K}$ \\
\hline \multicolumn{11}{|c|}{\begin{tabular}{|c|c|c|c|c|}
$\%$ characterized as & & as \\
\end{tabular}} \\
\hline $\mathrm{LTV}=80$ & \multicolumn{5}{|c|}{14.4} & \multicolumn{5}{|c|}{21.7} \\
\hline Subprime & \multicolumn{5}{|c|}{6.8} & \multicolumn{5}{|c|}{47.4} \\
\hline Fixed & \multicolumn{5}{|c|}{71.2} & \multicolumn{5}{|c|}{39.7} \\
\hline Hybrid ARM & \multirow{2}{*}{\multicolumn{5}{|c|}{$\begin{array}{c}7.7 \\
11.3\end{array}$}} & \multirow{2}{*}{\multicolumn{5}{|c|}{26.2}} \\
\hline IO-ARM & & & & & & & & & & \\
\hline IO-Fixed & \multicolumn{5}{|c|}{2.1} & \multicolumn{5}{|c|}{$\begin{array}{l}13.1 \\
2.7\end{array}$} \\
\hline Option-ARM & \multirow{2}{*}{\multicolumn{5}{|c|}{5.1}} & \multicolumn{5}{|c|}{12.0} \\
\hline Option-Fixed & & & & & & \multicolumn{5}{|c|}{1.4} \\
\hline Owner & \multicolumn{5}{|c|}{89.3} & \multicolumn{5}{|c|}{96.0} \\
\hline Investor & \multirow{2}{*}{\multicolumn{5}{|c|}{7.1}} & \multirow{2}{*}{\multicolumn{5}{|c|}{2.6}} \\
\hline Vacation Home & \multicolumn{2}{|c|}{3.7} & & & & & & & & 1.1 \\
\hline Purchase & \multicolumn{5}{|c|}{51.9} & \multicolumn{5}{|c|}{49.0} \\
\hline Low/no documentation & \multicolumn{5}{|c|}{29.2} & \multicolumn{5}{|c|}{20.4} \\
\hline
\end{tabular}

Notes: These statistics were computed using a 10\% random sample of the LPS data. Quantities obtained from the data are multiplied by a factor of 10. The percentages in panels (1) and (2) are taken with respect to the total number of modifications, and not loans modified. Thus, there is double-counting in the sense that some loans received multiple types of modifications in a given quarter. 
Table 4: Modification Comparison by Payment Change

\begin{tabular}{|c|c|c|c|c|c|c|c|c|c|c|}
\hline \multicolumn{11}{|c|}{ "Private-label Modifications } \\
\hline & \multicolumn{5}{|c|}{ Payment Decreases } & \multicolumn{5}{|c|}{ Payment Increases } \\
\hline & \multirow[t]{2}{*}{ \# } & \multicolumn{2}{|c|}{ mean } & \multicolumn{2}{|c|}{ median } & \multirow[t]{2}{*}{ \# } & \multicolumn{2}{|c|}{ mean } & \multicolumn{2}{|c|}{ median } \\
\hline & & $\$$ & $\%$ & $\$$ & $\%$ & & $\$$ & $\%$ & $\$$ & $\%$ \\
\hline 2007:Q1 & 106 & -614 & -14.42 & -162 & -10.85 & 239 & 121 & 6.02 & 76 & 3.37 \\
\hline 2007:Q2 & 110 & -505 & -12.02 & -222 & -9.30 & 364 & 168 & 7.96 & 76 & 3.49 \\
\hline 2007:Q3 & 128 & -261 & -11.82 & -131 & -8.42 & 558 & 145 & 7.52 & 75 & 3.65 \\
\hline 2007:Q4 & 288 & -313 & -13.38 & -163 & -12.36 & 741 & 125 & 6.24 & 74 & 3.52 \\
\hline 2008:Q1 & 634 & -393 & -16.12 & -261 & -15.65 & 938 & 133 & 6.76 & 79 & 4.08 \\
\hline 2008:Q2 & 1,014 & -540 & -18.94 & -334 & -17.89 & 1,241 & 152 & 8.14 & 83 & 4.08 \\
\hline 2008:Q3 & 1,778 & -641 & -22.01 & -423 & -19.95 & 1,805 & 137 & 6.22 & 70 & 3.31 \\
\hline 2008:Q4 & 1,993 & -565 & -21.73 & -367 & -20.13 & 1,398 & 118 & 5.91 & 61 & 3.23 \\
\hline \multicolumn{11}{|c|}{ Portfolio Modifications } \\
\hline & \multicolumn{5}{|c|}{ Payment Decreases } & \multicolumn{5}{|c|}{ Payment Increases } \\
\hline & \multirow[t]{2}{*}{ \# } & \multicolumn{2}{|c|}{ mean } & \multicolumn{2}{|c|}{ median } & \multirow[t]{2}{*}{ \# } & \multicolumn{2}{|c|}{ mean } & \multicolumn{2}{|c|}{ median } \\
\hline & & $\$$ & $\%$ & $\$$ & $\%$ & & $\$$ & $\%$ & $\$$ & $\%$ \\
\hline 2007:Q1 & 28 & -759 & \begin{tabular}{|l|}
-20.90 \\
\end{tabular} & -428 & -17.19 & 128 & 106 & 7.78 & 52 & 5.46 \\
\hline 2007:Q2 & 19 & -1172 & -25.17 & -656 & -28.07 & 222 & 81 & 6.11 & 55 & 5.28 \\
\hline 2007:Q3 & 31 & -395 & -17.13 & -168 & -15.29 & 255 & 71 & 6.13 & 43 & 5.37 \\
\hline 2007:Q4 & 90 & -474 & -11.11 & -90 & -2.48 & 292 & 70 & 5.50 & 37 & 4.29 \\
\hline 2008:Q1 & 187 & -369 & -10.00 & -183 & -8.08 & 331 & 80 & 6.59 & 33 & 3.97 \\
\hline 2008:Q2 & 309 & -304 & -10.90 & -117 & -6.64 & 405 & 63 & 5.59 & 34 & 3.56 \\
\hline 2008:Q3 & 376 & -585 & -25.19 & -295 & -17.85 & 359 & 105 & 7.04 & 39 & 4.26 \\
\hline 2008:Q4 & 616 & -794 & -31.91 & -384 & -25.04 & 389 & 59 & 5.48 & 35 & 3.51 \\
\hline
\end{tabular}


Table 5: Modifications (Main Sample)

\begin{tabular}{|c|c|c|c|}
\hline \multicolumn{4}{|c|}{ Panel A: Unconditional Percentages } \\
\hline & $\begin{array}{c}\text { Concessionary } \\
\text { Mods }\end{array}$ & All Mods & $\begin{array}{l}\text { All Mods + } \\
\text { Prepayments }\end{array}$ \\
\hline Portfolio & 0.032 & 0.087 & 0.147 \\
\hline Private-label & 0.026 & 0.084 & 0.155 \\
\hline
\end{tabular}

Panel B: Logit Regressions (12 month horizon)

\begin{tabular}{l|ccc} 
& $\begin{array}{c}\text { Concessionary } \\
\text { Mods }\end{array}$ & All Mods & All Mods + \\
Prepayments
\end{tabular}

Panel C: Duration Model

\begin{tabular}{l|ccc} 
& $\begin{array}{c}\text { Concessionary } \\
\text { Mods }\end{array}$ & All Mods & $\begin{array}{c}\text { All Mods + } \\
\text { Prepayments }\end{array}$ \\
\hline Private-label & 0.921 & 1.002 & 1.018 \\
& -1.41 & 0.07 & 0.68 \\
\hline \# Mortgages & 87,343 & 87,343 & 87,343 \\
\hline \hline
\end{tabular}

Notes: Other controls include indicator variables for Jumbo, Option, Hybrid and Interest-Only mortgages, as well as for condos and multifamily homes. Panel B shows the marginal effects of logit regressions with a 12-month horizon, t-statistics shown below the coefficients. Standard errors are clustered at the zip code level. Panel $\mathrm{C}$ shows hazard ratio estimates from a Cox proportional hazards model. 
Table 6: Modifications (Robustness tests with alternative samples)

\begin{tabular}{l|ccccc}
\hline \hline \multicolumn{7}{c}{ Panel A: Concessionary Modifications } \\
& All Loans & Subprime & $F I C O<620$ & $\begin{array}{c}\text { Non-missing } \\
\text { Documentation and DTI }\end{array}$ & Fully Documented \\
\hline $\begin{array}{l}\text { Portfolio Mean } \\
\text { Private-label Mean }\end{array}$ & 0.032 & 0.047 & 0.034 & 0.028 & 0.023 \\
& 0.026 & 0.037 & 0.031 & 0.033 & 0.037 \\
$\begin{array}{l}\text { Marginal Effect } \\
\text { (private-label) }\end{array}$ & -0.003 & -0.004 & -0.003 & 0 & 0.007 \\
\hline \# Mortgages & -1.69 & -0.94 & -0.77 & -0.14 & 1.46 \\
\hline
\end{tabular}

Panel B: All Modifications

\begin{tabular}{l|ccccc} 
& All Loans & Subprime & $F I C O<620$ & $\begin{array}{c}\text { Non-missing } \\
\text { Documentation and DTI }\end{array}$ & Fully Documented \\
\hline Portfolio Mean & 0.087 & 0.111 & 0.097 & 0.092 & 0.077 \\
Private-label Mean & 0.084 & 0.103 & 0.109 & 0.107 & 0.124 \\
& & & & & 0.006 \\
Marginal Effect & 0.002 & 0.004 & 0.007 & 0.97 & 2.94 \\
(private-label) & 0.58 & 0.61 & 1.06 & 25,543 & 18,097 \\
\hline \# Mortgages & 66,541 & 33,719 & 27,639 & & \\
\hline \hline
\end{tabular}

Notes: Portfolio and private-label means are unconditional probabilities of modification in each sample. Marginal effects are computed from logit models with a 12-month horizon that include all the controls in Table 5. Standard errors are clustered at the zip code level. t-statistics are reported below the marginal effects. 
Table 7: Modifications Conditional on 30 Days Delinquency (Logits)

\begin{tabular}{l|ccccc}
\hline \hline \multicolumn{5}{c}{ Panel A: Concessionary Mods } \\
& All Loans & Subprime & FICO $<620$ & $\begin{array}{c}\text { Non-missing } \\
\text { Documentation and DTI }\end{array}$ & Fully Documented \\
\hline Portfolio Mean & 0.014 & 0.025 & 0.016 & 0.014 & 0.012 \\
Private-label Mean & 0.014 & 0.021 & 0.016 & 0.017 & 0.019 \\
Marginal Effect & -0.003 & -0.005 & -0.001 & -0.002 & 0.001 \\
(Logit) & -2.72 & -2.31 & -0.55 & -1.57 & 0.37 \\
Hazard Ratio & 1.03 & 1.147 & 1.027 & 0.969 & 1.237 \\
(Cox) & 0.59 & 1.83 & 0.31 & -0.42 & 2.34 \\
\hline \# Mortgages & 120,558 & 51,285 & 43,550 & 47,993 & 34,403 \\
\hline
\end{tabular}

Panel B: All Mods

\begin{tabular}{l|ccccc} 
& All Loans & Subprime & $F I C O<620$ & $\begin{array}{c}\text { Non-missing } \\
\text { Documentation and DTI }\end{array}$ & Fully Documented \\
\hline Portfolio Mean & 0.038 & 0.056 & 0.051 & 0.042 & 0.052 \\
Private-label Mean & 0.042 & 0.055 & 0.051 & 0.047 & 0.035 \\
Marginal effect & -0.004 & -0.007 & -0.004 & -0.008 & -0.001 \\
(Logit) & -2.39 & -1.79 & -1.22 & -3.16 & -0.2 \\
& & & & & 0.909 \\
Hazard Ratio & 1.043 & 0.951 & 1.008 & -2.23 & 1.065 \\
(Cox) & 1.42 & -1.05 & 0.17 & 47,993 & 34,403 \\
\hline \# Mortgages & 120,558 & 51,285 & 43,550 & & \\
\hline
\end{tabular}

Panel C: All Mods + Prepayment

\begin{tabular}{l|ccccc} 
& All Loans & Subprime & $F I C O<620$ & $\begin{array}{c}\text { Non-missing } \\
\text { Documentation and DTI }\end{array}$ & Fully Documented \\
\hline Portfolio Mean & 0.145 & 0.195 & 0.152 & 0.147 & 0.13 \\
Private-label Mean & 0.174 & 0.211 & 0.218 & 0.185 & 0.198 \\
Marginal effect & 0.023 & 0.021 & 0.044 & 0.016 & 0.029 \\
(Logit) & 7.31 & 2.98 & 6.46 & 3.47 & 4.54 \\
& & & & & 1.202 \\
Hazard Ratio & 1.158 & 1.05 & 1.181 & 3.89 & 6.56 \\
(Cox) & 9.09 & 1.69 & 5.72 & 47,993 & 34,403 \\
\hline \# Mortgages & 120,558 & 51,285 & 43,550 & & \\
\hline \hline
\end{tabular}

Notes: Portfolio and private-label means are unconditional probabilities of modification in each sample. Marginal effects are computed from logit models with a 12-month horizon that include all the controls in Table 5. Hazard ratios are computed from Cox proportional hazard models with the same controls as in Table 5. z-statistics are shown below the coefficients, and t-statistics are reported below the marginal effects. Standard errors are clustered at the zip code level. Sample sizes refer to the logit regressions. The sample sizes for the Cox models are slightly larger. 
Table 8: redefault Conditional on Modification

\begin{tabular}{l|ccccc}
\hline \hline \multicolumn{5}{c}{} & \multicolumn{5}{c}{ Panel A: Payment Reducing Mods } \\
& All Loans & Subprime & $F I C O<620$ & $\begin{array}{c}\text { Non-missing } \\
\text { Documentation and DTI }\end{array}$ & Fully Documented \\
\hline $\begin{array}{l}\text { Portfolio Mean } \\
\text { Private-label Mean }\end{array}$ & 0.308 & 0.386 & 0.332 & 0.228 & 0.249 \\
& 0.358 & 0.392 & 0.371 & 0.362 & 0.359 \\
$\begin{array}{l}\text { Marginal effect } \\
\text { (Logit) }\end{array}$ & 0.016 & -0.001 & -0.015 & 0.03 & -0.004 \\
\hline \# Mortgages & 0.66 & -0.03 & -0.35 & 0.81 & -0.1 \\
\hline
\end{tabular}

Panel B: All Mods

\begin{tabular}{l|ccccc} 
& All Loans & Subprime & $F I C O<620$ & $\begin{array}{c}\text { Non-missing } \\
\text { Documentation and DTI }\end{array}$ & Fully Documented \\
\hline Portfolio Mean & 0.393 & 0.53 & 0.444 & 0.404 & 0.403 \\
Private-label Mean & 0.449 & 0.5 & 0.501 & 0.482 & 0.482 \\
& & & & & -0.033 \\
Marginal effect & 0.008 & -0.023 & -0.009 & -0.021 & -1.24 \\
\hline Logit) & 0.58 & -0.84 & -0.38 & -0.97 & 3,620 \\
\hline \# Mortgages & 14,796 & 7,073 & 5,344 & 4,594 & \\
\hline \hline
\end{tabular}

Notes: redefault is defined as loans that are 60 days delinquent, 90 days delinquent, in the process of foreclosure or in REO 6 months after the modification. Marginal Effects refer to the marginal effects of a logit model with a horizon of 6 months. t-statistics shown below the marginal effects. Standard errors are clustered at the zip code level.

Table 9: Cure Conditional on 60 Days Delinquency

\begin{tabular}{l|ccccc}
\hline \hline & All Loans & Subprime & FICO $<620$ & $\begin{array}{c}\text { Non-missing } \\
\text { Documentation and DTI }\end{array}$ & Fully Documented \\
\hline Portfolio Mean & 0.300 & 0.257 & 0.320 & 0.280 & 0.299 \\
Private-label Mean & 0.256 & 0.289 & 0.328 & 0.289 & 0.324 \\
& & & & & 0.022 \\
Marginal effect & -0.022 & 0.043 & 0.004 & 2.8 & 0.025 \\
(Logit) & -4.32 & 4.31 & 0.44 & 25,543 & 18,097 \\
\hline \# Mortgages & 66,451 & 33,719 & 27,639 & & \\
\hline \hline
\end{tabular}

Notes: The dependent variable ("Cure") is defined as a loan that is either current, 30 days delinquent, or prepaid 12 months after the first 60-day delinquency. Portfolio and Private-label means are unconditional probabilities of modification in each sample. Marginal effects are computed from logit models with a 12month horizon that include all the controls in Table 5. Standard errors are clustered at the zip code level. t-statistics are reported below the marginal effects. 
Figure 1:

\section{(1) Model of loan modification}

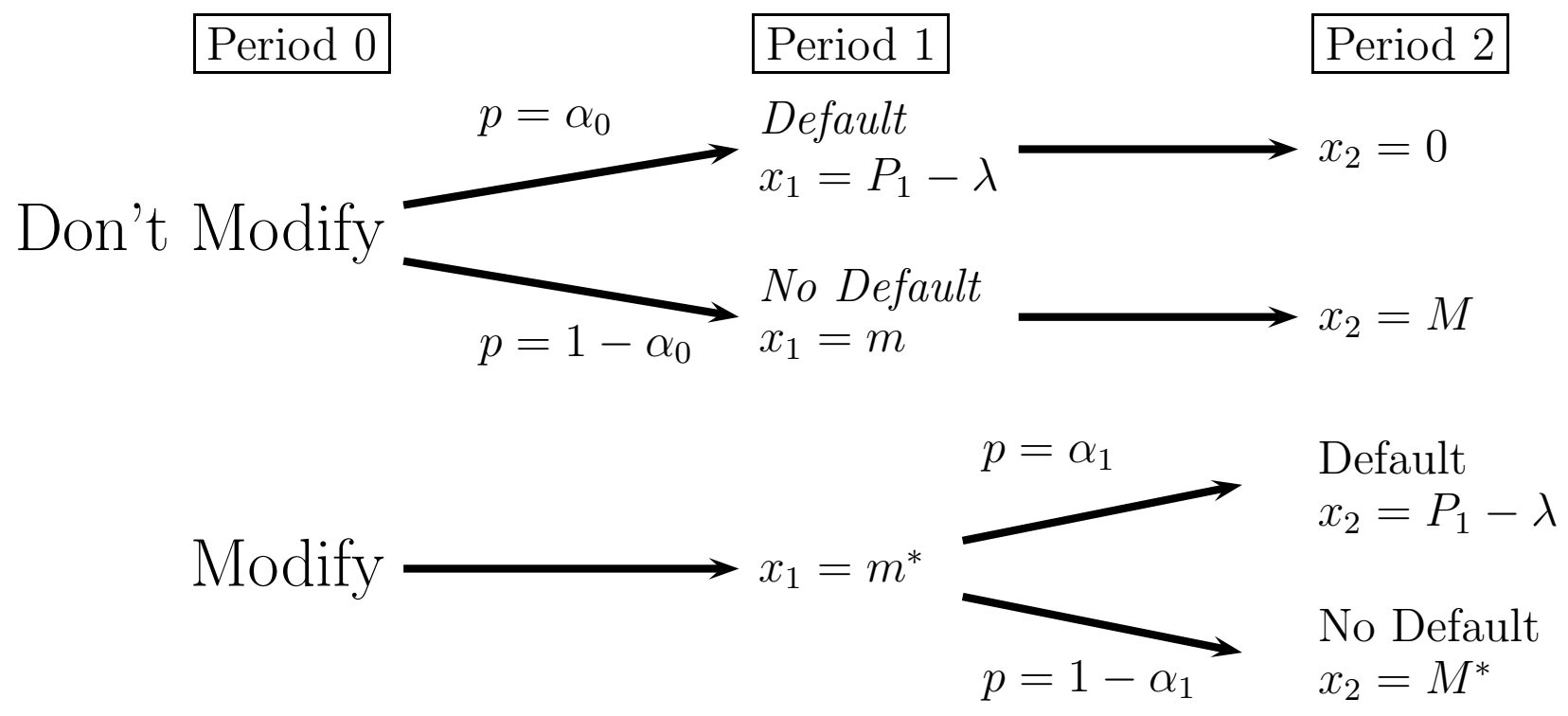

(2) Understanding the lender's gains from modification

\begin{tabular}{|c|c|c|c|}
\hline $\begin{array}{l}\text { Share of } \\
\text { borrowers }\end{array}$ & $1-\alpha_{0}$ & $\alpha_{0}-\alpha_{1}$ & $\alpha_{1}$ \\
\hline & Borrower always repays & Modification effective & Borrower never repays \\
\hline Description & $\begin{array}{c}\text { Lender loses because } \\
\text { borrower would have } \\
\text { paid in full }\end{array}$ & $\begin{array}{l}\text { Lender gains because } \\
\text { modified payments } \\
\text { worth more than } \\
\text { foreclosure }\end{array}$ & $\begin{array}{c}\text { Foreclosure is delayed } \\
\text { May or may not help } \\
\text { lender }\end{array}$ \\
\hline Net gain & $m^{*}+\frac{1}{R} M^{*}-\left(m+\frac{1}{R} M\right)$ & $m^{*}+\frac{1}{R} M^{*}-\left(P_{1}-\lambda\right)$ & $m^{*}+\frac{1}{R}\left(P_{2}-\lambda\right)-\left(P_{1}-\lambda\right)$ \\
\hline Error & $\begin{array}{c}\text { "Type II error" } \\
\text { Costly assistance to } \\
\text { borrowers who can pay }\end{array}$ & $\begin{array}{l}\text { "Type I error" } \\
\text { Don't help borrowers } \\
\text { who would have } \\
\text { defaulted }\end{array}$ & $\begin{array}{l}\text { "Type III error" } \\
\text { Lender loses if } R \text { is large } \\
\text { or if } P_{1}-P_{2} \text { is big }\end{array}$ \\
\hline
\end{tabular}

